\title{
Evidence of Predation on Nestling Birds by Eastern Gartersnakes (Thamnophis sirtalis sirtalis)
}

\author{
WiLLIAM D. HALLIDAY \\ Department of Biology, University of Ottawa, 30 Marie Curie, Ottawa, Ontario K1N 6N5 Canada; email: whall075@uottawa.ca \\ Halliday, William D. 2016. Evidence of predation on nestling birds by Eastern Gartersnakes (Thamnophis sirtalis sirtalis). \\ Canadian Field-Naturalist 130(2): 146-151.
}

Diet is an important aspect of the natural history of all animals, but diet can vary through space and time because of variations in prey availability. The diet of the Common Gartersnake (Thamnophis sirtalis) consists mainly of earthworms and frogs, but other prey items might be important when they are locally abundant. I report an observation of a female Eastern Gartersnake (Thamnophis sirtalis sirtalis) regurgitating 2 nestling birds in Ottawa, Ontario, Canada. Birds are seldom present in the diet of the Common Gartersnake. This rare food choice highlights the opportunistic nature of foraging by adult Common Gartersnakes and, further, demonstrates that diet depends not only on prey preference, but also on prey availability.

Key Words: Diet; Eastern Gartersnake; Thamnophis sirtalis sirtalis; nestling; predation; prey preference; prey selection; Eastern Ontario

Prey preference and diet are important aspects of the natural history of all animals. Diet often depends not only on the prey preference of the species, but also on the availability of prey, which changes with space, time, and ontogeny (Carpenter 1952). If the preferred prey is less available, then diet may consist of a less preferred but more available prey item (Gregory and Nelson 1991).

The diet of the Common Gartersnake (Thamnophis sirtalis) consists mainly of earthworms and frogs (Rowell 2012), although it often contains many other prey items, including fish, small mammals, slugs, leeches, and occasionally birds and other snakes (Table 1). When the prevalence of prey species is averaged across studies, Common Gartersnakes show a strong preference for frogs, followed closely by earthworms, while salamanders, fish, and mammals occur in their diet less frequently, and all other prey items can be considered rare (Table 2). Studies of prey preference demonstrate that Common Gartersnakes almost exclusively eat earthworms when they are small and incorporate larger food items, such as amphibians, into their diet as they grow larger (Carpenter 1952; Gregory 1978; Halloy and Burghardt 1990; Gregory and Nelson 1991), a practice that is likely related to gape-size limitation (Halloy and Burghardt 1990; Rodriguez-Robles et al. 1999).

The diet of Common Gartersnakes is constrained by prey availability. Gregory and Nelson (1991) compared the diets of Common Gartersnakes living near fish hatcheries and those living at reference sites away from hatcheries. Fish were the dominant prey item in stomachs of snakes from the fish hatchery, and amphibians and earthworms were the dominant prey items in snakes from reference sites. A similar pattern has been observed on islands with nesting colonies of birds (Fetterolf 1979;

Greenwell et al. 1984), although these researchers did not compare the diets of Common Gartersnakes, but rather observed Common Gartersnakes eating nestling birds at locations where they were abundant. One of these studies (Greenwell et al. 1984) examined the prey preference of Common Gartersnakes in the laboratory by presenting them with various food items, including birds. Common Gartersnakes from the island that had been observed eating nestling terns had a similar prey preference to snakes from the mainland: both populations preferred frogs, followed by earthworms and fish; birds were rarely consumed. This study suggests that prey preference in Common Gartersnakes is engrained, but increased availability of a non-preferred food item can increase its prevalence in their diet.

Here, I document an example of an Eastern Gartersnake (Thamnophis sirtalis sirtalis) that ate nestling birds. In July 2015, I encountered a female Eastern Gartersnake (snout-vent length: $536 \mathrm{~mm}$; mass after regurgitation: $64 \mathrm{~g}$; Figure 1) moving along the shore of the Ottawa River near Britannia Conservation Area, Ottawa, Ontario, Canada $\left(45.375036^{\circ} \mathrm{N}, 75.786887^{\circ} \mathrm{W}\right.$; WGS 84). The snake was in a habitat dominated by ferns and forbs no more than $50 \mathrm{~cm}$ tall. I noted that it had a large food bulge. After I handled the snake, it regurgitated 2 nestling sparrows: 1 was partly decomposed and the other was mostly intact (body length: $58 \mathrm{~mm}$; wing length: $23 \mathrm{~mm}$; mass: $8 \mathrm{~g}$; Figure 2). I was unable to identify the birds confidently to species because of decomposition and incomplete plumage, but they were likely a species that nests on the ground or in low shrubs, which would increase the chances of a gartersnake coming across the nest.

Based on the rarity of birds in the diet of Common Gartersnakes and the fact that in almost all reported

A contribution towards the cost of this publication has been provided by the Thomas Manning Memorial Fund of the Ottawa Field-Naturalist's Club. 


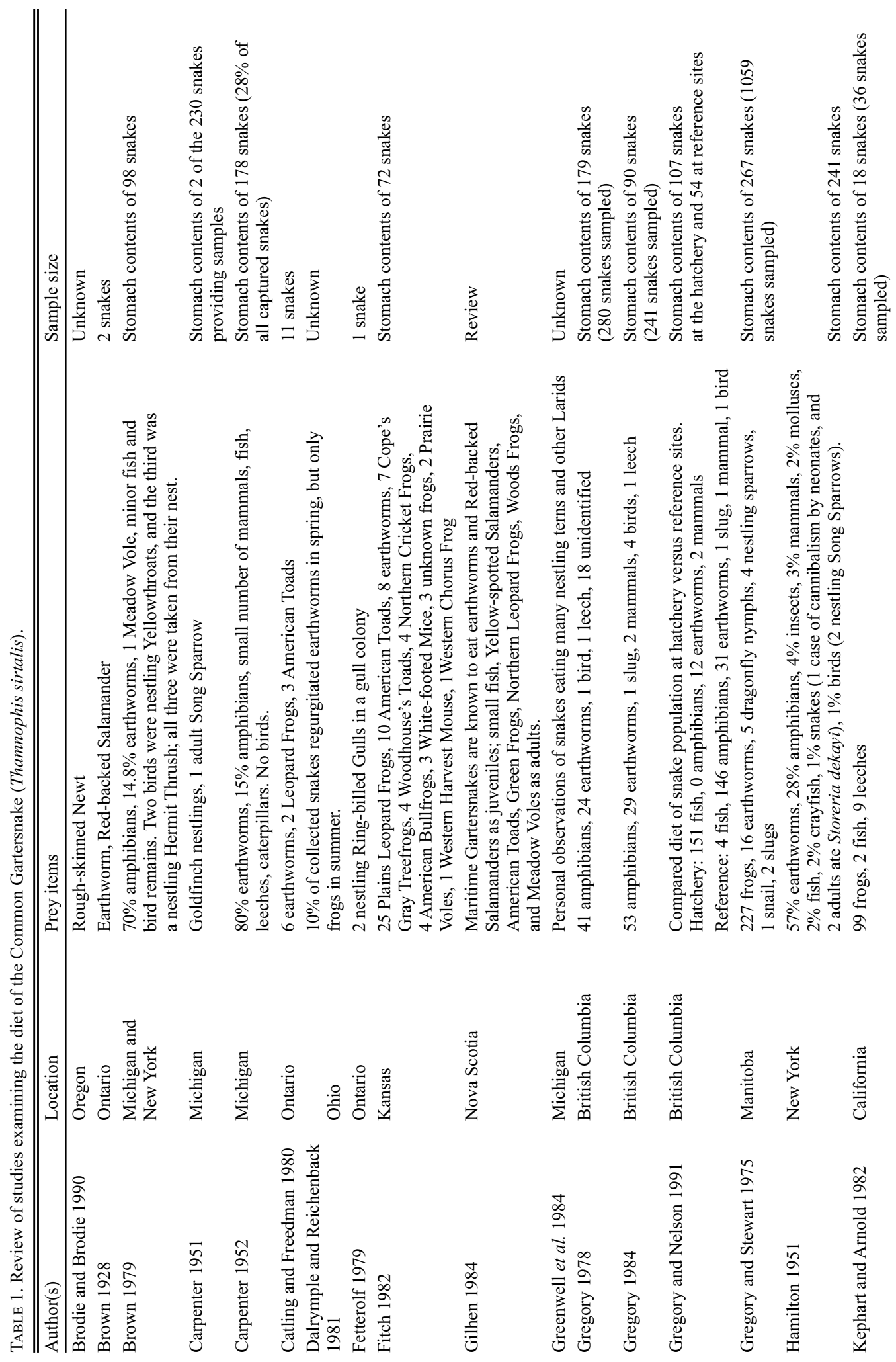


incidents of such prey, the birds have been nestlings or fledglings, I hypothesize that large Common Gartersnakes are opportunistic foragers that will eat any vertebrate or invertebrate they encounter as long as they can successfully swallow it and it is within their range of food choices. The gape-size limitation has been demonstrated in captive Common Gartersnakes, where larger snakes were able to consume larger fish (Halloy and Burghardt 1990). However, this is not to negate the frequently observed preference of Common Gartersnakes for earthworms and amphibians (Table 2). Given the relatively recent introduction of earthworms to North America (Hendrix and Bohlen 2002), the preference of Common Gartersnakes for earthworms is a clear example of opportunism in diet selection.

Greenwell et al. (1984) conducted an interesting trial in which 12 Common Gartersnakes were presented with bird carcasses, and none consumed the birds. Yet when the researchers infused the bird carcasses with the smell of fish, 9 of the 12 Common Gartersnakes ate the birds. This novel result suggests Common Gartersnakes do not generally consider birds to be a prey item, but do so when they smell like other preferred prey items. In the case of nestling birds, if their parents are feeding them worms frequently, then perhaps the smell of worms on the birds makes them a preferred prey of gartersnakes.

The natural history of most birds likely makes them an inaccessible prey for Common Gartersnakes. Most adult birds are likely quick and agile enough to escape predation by gartersnakes. Many birds also nest in trees, making them largely inaccessible to gartersnakes. Conversely, amphibians and earthworms are often abundant in habitats occupied by Common Gartersnakes, likely because of a shared habitat preference (Halliday, unpublished data) and their terrestrial habit. Thus, amphibians and earthworms are an easily accessible prey item for Common Gartersnakes. Birds, on the other hand, spend most of their time off of the ground and are, therefore, usually inaccessible to Common Gartersnakes; however, nestling birds in ground nests and fledgling birds are exceptions to this. Nestlings and fledglings can potentially become part of the diet of Common Gartersnakes for a short time every year, just as smaller frogs become part of the Common Gartersnake diet when they metamorphose and leave the water body in which they developed (Carpenter 1952; Gregory 1984). It is possible that Common Gartersnakes evolved a general preference for earthworms and amphibians because of their accessibility throughout the active season.

In conclusion, nestling and fledgling birds are a part, however rare, of the diet of Common Gartersnakes. In areas with a high density of ground nests and fledglings, young birds could make up a substantial part of the Common Gartersnake diet during part of the summer (Fetterolf 1979; Greenwell et al. 1984). 
TABLE 2. The diet of Common Gartersnakes (Thamnophis sirtalis), based on 25 reviewed publications (see Table 1). Slugs and snails were combined into 1 category (Molluscs), and caterpillars and dragonfly nymphs were combined into 1 category (Insects).

\begin{tabular}{lccc}
\hline \hline Prey & No. studies* & Mean rank $\dagger$ & Absolute rank $\$$ \\
\hline Frogs and toads & 16 & 2.1 & 1 \\
Earthworms & 14 & 4.1 & 2 \\
Salamanders & 12 & 6.1 & 3 \\
Fish & 10 & 6.5 & 4 \\
Mammals & 9 & 6.5 & 4 \\
Leeches & 8 & 7.9 & 6 \\
Birds & 13 & 8.5 & 7 \\
Insects & 5 & 8.5 & 9 \\
Molluscs & 6 & 8.8 & 10 \\
Crayfish & 2 & 10.8 & 11 \\
Snakes & 2 & 10.9 & \\
\hline \hline
\end{tabular}

*Number of references (including review articles and books) that mention each prey item.

$\dagger$ Mean rank order $(1=$ highest preference) of prey items in the diet of Common Gartersnakes based on the 15 studies that sampled stomach contents of multiple snakes. Mean rank order was calculated by ranking prey items based on their prevalence in each study, from 1 to 11 (total number of possible prey items), then calculating the mean for each prey item across all 15 studies. Prey items not found in a study were given a rank of 11.

†Absolute rank was calculated as the rank of the mean ranks for each prey item.

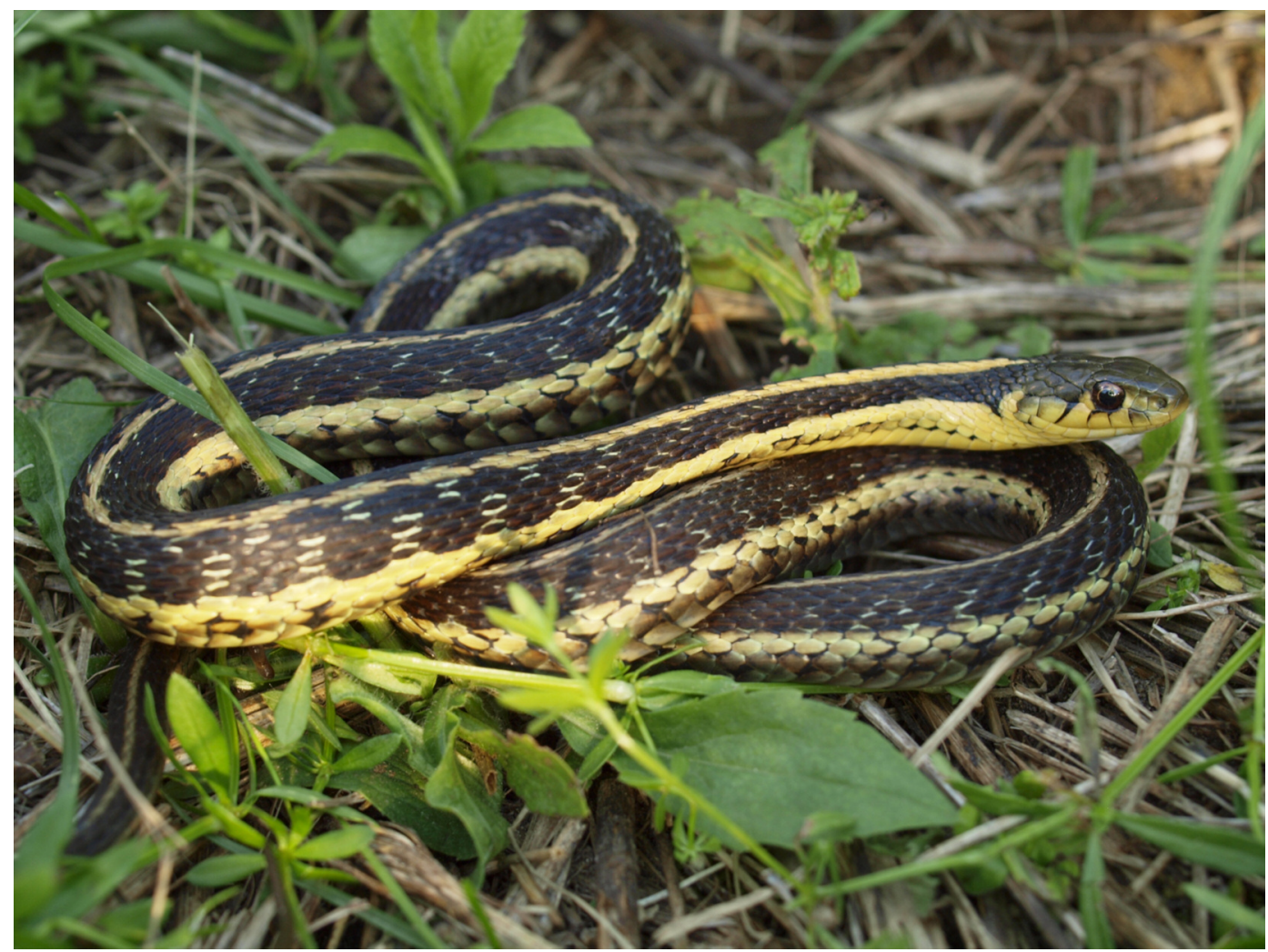

FIGURE 1. Female Eastern Gartersnake (Thamnophis sirtalis sirtalis) encountered in Ottawa, Ontario, Canada, that regurgitated 2 nestling birds. Snout-vent length $=536 \mathrm{~mm}$, mass $=64 \mathrm{~g}$. Photo: William D. Halliday. 


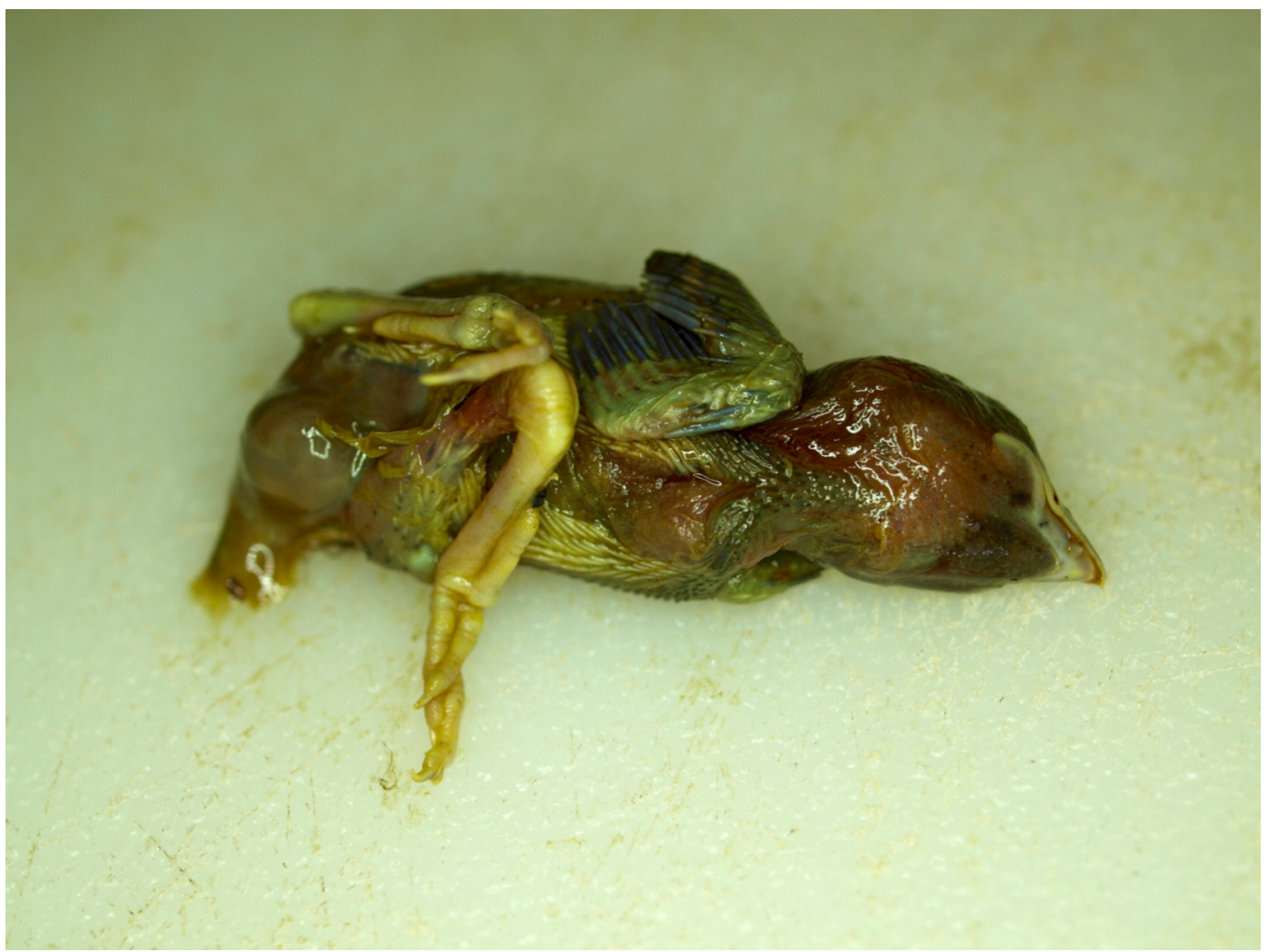

FIGURE 2. Nestling bird regurgitated by an Eastern Gartersnake (Thamnophis sirtalis sirtalis) encountered in Ottawa, Ontario, Canada. Body length $=58 \mathrm{~mm}$, wing length $=23 \mathrm{~mm}$, mass $=8 \mathrm{~g}$. Photo: William D. Halliday.

\section{Acknowledgements}

I am grateful to the National Capital Commission for the use of their property. This research was approved by the University of Ottawa's Animal Care Committee and by the Ontario Ministry of Natural Resources. Funding was provided by a Natural Sciences and Engineering Research Council of Canada postgraduate scholarship and an Ottawa Field-Naturalists' Club research grant. I am also grateful to 3 anonymous reviewers for their helpful comments, which improved the quality and clarity of this contribution.

\section{Literature Cited}

Brodie III, E. D., and E. D. Brodie Jr. 1990. Tetrodotoxin resistance in garter snakes: an evolutionary response of predators to dangerous prey. Evolution 44: 651-659.

Brown, R. 1928. The herpetology of Hamilton, Ontario, and district. Canadian Field-Naturalist 42: 125-127.

Carpenter, C. C. 1951. Young goldfinches eaten by garter snake. Wilson Bulletin 63: 117-118.

Carpenter, C. C. 1952. Comparative ecology of the Common Garter Snake (Thamnophis s. sirtalis), the Ribbon Snake (Thamnophis s. sauritus), and Butler's Garter Snake (Thamnophis butleri) in mixed populations. Ecological Monographs 22: 235-258.
Catling, P. M., and B. Freedman. 1980. Food and feeding behaviour of sympatric snakes at Amherstburg, Ontario. Canadian Field-Naturalist 94: 28-33.

Dalrymple, G. H., and N. G. Reichenbach. 1981. Interactions between the prairie garter snake (Thamnophis radix) and the common garter snake (T. sirtalis) in Killdeer Plains, Wyandot County, Ohio. Ohio Biological Survey Biology Notes 15: 244-250.

Fetterolf, P. M. 1979. Common garter snake predation on ring-billed gull chicks. Canadian Field-Naturalist 93: 317 318.

Fitch, H. S. 1982. Resources of a snake community in prairiewoodland habitat of northeastern Kansas. Pages 83-97 in Herpetological Communities. Wildlife research report 13. Edited by N. J. Scott. United States Fish and Wildlife Service, Washington, DC, USA.

Gilhen, J. 1984. Amphibians and Reptiles of Nova Scotia. Nova Scotia Museum, Halifax, Nova Scotia, Canada.

Greenwell, M. G., M. Hall, and O. J. Sexton. 1984. Phenotypic basis for a feeding change in an insular population of garter snake. Developmental Psychology 17: 457-463.

Gregory, P. T. 1978. Feeding habits and diet overlap of three species of garter snake (Thamnophis) on Vancouver Island. Canadian Journal of Zoology 56: 1967-1974.

Gregory, P. T. 1984. Habitat, diet, and composition of assemblages of garter snakes (Thamnophis) at eight sites on Van- 
couver Island. Canadian Journal of Zoology 62: 20132022.

Gregory, P. T., and K. J. Nelson. 1991. Predation on fish and intersite variation in the diet of common garter snakes, Thamnophis sirtalis, on Vancouver Island. Canadian Journal of Zoology 69: 988-994.

Gregory, P. T., and K. W. Stewart. 1975. Long-distance dispersal and feeding strategy of the red-sided garter snake (Thamnophis sirtalis parietalis) in the Interlake of Manitoba. Canadian Journal of Zoology 53: 238-245.

Halloy, M., and G. M. Burghardt. 1990. Ontogeny of fish capture and ingestion in four species of garter snakes (Thamnophis). Behaviour 112: 299-318.

Hamilton, W. J., Jr. 1951. The food and feeding behavior of the garter snake in New York State. American Midland Naturalist 46: 385-390.

Hendrix, P. F., and P. J. Bohlen. 2002. Exotic earthworm invasions in North America: ecological and policy implications. Bioscience 52: 801-811.

Kephart, D. G., and S. J. Arnold. 1982. Garter snake diets in a fluctuating environment: a seven-year study. Ecology 63: $1232-1236$
Lagler, K. F., and J. C. Salyer II. 1945. Influence of availability on the feeding habits of the common garter snake. Copeia 1945: 159-162.

Logier, E. B. S. 1925. Notes on the herpetology of Point Pelee, Ontario. Canadian Field-Naturalist 39: 91-35.

Rodriguez-Robles, J. A., C. J. Bell, and H. W. Greene. 1999. Gape size and the evolution of diet in snakes: feeding ecology of erycine boas. Journal of Zoology 248: 49-58.

Rossman, D. A., N. B. Ford, and R. A. Seigel. 1996. The Garter Snakes: Evolution and Ecology. University of Oklahoma Press, Norman, Oklahoma, USA.

Rowell, J. C. 2012. The Snakes of Ontario: Natural History, Distribution, and Status. Art Bookbindery, Winnipeg, Manitoba, Canada.

Walkinshaw, L. H. 1943. Snakes destroying birds' eggs and young. Wilson Bulletin 55: 56.

White, M., and J. Kolb. 1974. A preliminary study of Thamnophis near Sagehen Creek, California. Copeia 1974: 126-136.

Accepted 3 August 2015

Received 28 February 2016 